\title{
THE INFLUENCE OF HOT-DEFORMATION PARAMETERS ON THE MECHANICAL PROPERTIES AND PRECIPITATION PROCESS IN NICKEL BASED SUPERALLOY
}

\author{
Andrzej Nowotnik \\ Department of Materials Science, Rzeszow University of Technology, W. Pola 2 Str., 35-959 Rzeszów, Poland
}

Keywords: Superalloy, Inconel 718, Dynamic Precipitation, Hot Working, Activation Energy

\begin{abstract}
Experimental results on hot deformation and dynamic structural processes of nickel based alloy Inconel 718 are reviewed. The focus is the analysis of dynamic precipitation processes which operate during hot deformation of these materials at elevated temperatures. Hot compression tests were performed on the solution treated precipitation hardenable nickel based superalloy Inconel 718 at $720-1150^{\circ} \mathrm{C}$ with a constant true strain rates of $10^{-4}$ and $4 \times 10^{-4} \mathrm{~s}^{-1}$. True stress - true strain curves and microstructure analysis of the deformed nickel based superalloy is presented. The properties and dynamic behaviour are explained through observation of the microstructure using standard optical, scanning and transmission electron microscopy. Structural observations of solution treated Inconel 718 deformed at high temperatures, reveal non uniform deformation effects. The distribution of molybdenum-rich and niobium-rich carbides were affected by localized flow within the strain range investigated at relatively low deformation temperatures $720-850^{\circ} \mathrm{C}$. Microstructural examination of the alloy also shows that shear banding, cavity growth and intergranular cracks penetrating through the whole grains were responsible for decreased flow stresses at temperature of 720,800 and $850^{\circ} \mathrm{C}$ and might result in sample fracture at larger strains. On the basis of the measured flow stress activation energies of high-temperature deformation processes were estimated. The mathematical dependence of the effect of flow stress on temperature and strain rate $\left(\sigma_{\mathrm{pl}}-\mathrm{T}\right.$ and $\left.\sigma_{\mathrm{pl}}-\dot{\varepsilon}\right)$ as well as compression data were used to determine material's constants. These constants allowed the derivation of a formula that describes the relationship between strain rate $(\dot{\varepsilon})$, deformation temperature (T) and flow stress $\sigma_{\mathrm{p}}$. Interaction of precipitates developed during deformation below the solvus temperature and heterogeneous deformation (flow localization) can become a significant aspect of high temperature performance of precipitation hardenable alloys. This interaction could also potentially allow production of specific microstructures in deformed materials. The contribution of flow localization to the strain hardening or flow softening and the flow stress-strain behavior during hot deformation of precipitation hardenable alloys is still a subject of extensive research.
\end{abstract}

\section{Introduction}

The capability of material to undergo plastic deformation is one of the most exceptional characteristics of metals and alloys. This capability is utilized in most forming operations to obtain the required final shape for many products. Obtaining the appropriate microstructure that guarantees suitable properties for the final product is the main goal of most forming operations. Subsequently chemical and phase composition, microstructure and technique of deformation or even its parameters plays a crucial role in the plastic deformation process. These factors affect the strengthening kinetics, the microstructure and thus the mechanical properties of a material. Cold and hot-working are the most frequently used techniques for forming metals and alloys. During cold-working, intermediate annealing is repeatedly required to remove the work hardening effect through recovery and recrystallization of the material. Both processes occur not only under static conditions but also under dynamic conditions in addition, i.e. during high temperature deformation. During the last decade the mechanisms involved in hot-working of metals and alloys have been extensively investigated. The most common softening mechanisms include dynamic recovery (DR) and dynamic recrystallization (DRX). At relatively low strain rates a precipitation process may operate during hot deformation of solution treated age hardenable alloys. This phenomenon is known as dynamic precipitation (DP), and is defined as precipitation during deformation of solution treated alloys below the solvus temperature. DP may interact with other structural processes during hot deformation and has an effect on the flow stress as well as the final microstructure and thus the properties of the material. DP usually increases the total hardening of the material due to retardation of both DR and DRX by dispersive particles growth. The amount of strengthening during hot deformation resulting from dynamically precipitated particles depend on their morphology, strength and distribution within the matrix. During hot deformation of age hardenable alloys the change of particle distribution and their morphology may also affect the microstructure and material properties. In particular, particle morphology may be affected by the dynamic coarsening of precipitates which might develop during hot deformation of some alloys.

A fundamental feature of plastic deformation is the homogeneity of strain distribution. It is commonly accepted that at low temperatures and high strains, flow localization may develop and affect the material ductility. On the other hand, hot-deformation at intermediate temperatures may also result in localized plastic flow and nonhomogenous deformation. Flow localization, as a result of substructure instability and collective motion of a large number of dislocations characterizes coarse slip or shear banding, Luders bands and the Portevin-LeChatelier effect. Kink bands and mechanical twins may also be considered as a individual form of flow localization. Coarse slip is usually used to describe the localized flow within individual grains, whereas shear bands traverse many grains very often without any significant relation to the position of easy glide systems plane. In pure metals and single phase alloys, shear bands have been found to be preferential sites for the nucleation of both static and dynamic recrystallization.

It is widely believed that in age hardenable alloys, shear bands and dislocation substructure produce preferred sites for nucleation of precipitates, thus enhancing the nucleation. These same features also are believed to enhance the particle growth rate during hot deformation as a result of higher vacancy concentration produced by intensive straining as well as increased dislocation pipe diffusion. The study of processes which are associated with dynamic aging of supersaturated solid solution during hot deformation may turn out to be very complicated because of the mutual interaction between dynamic precipitation and the structure resulting from the deformation process. The stress-strain 709 curves for metals and alloys obtained during hot deformation are typically characterized by an initial hardening followed by either 
steady-state flow, single-peak or multipeaks behavior depending on the material, deformation temperature and strain rate. It has been reported that for materials which display steady-state flow after an initial hardening range, the flow stress level was controlled by a sole DR process. Generally, $\sigma-\varepsilon$ characteristic with the flow stress increasing to a peak (initial strain hardening) and then decreasing to a steady state is typical for hot working accompanied by DRX. The modification of particle morphology and/or the material texture may also result in the development of a flow stress peak. Localized plastic flow has been found to be responsible for flow softening after the initial peak in some hot deformed materials. Therefore flow softening can not be used for a simple DRX detection and careful structural observations should always be performed to analyze structural processes which are responsible for the material softening during hot deformation.

The contribution of flow localization to the strain hardening or flow softening and the flow stress-strain behavior during hot deformation of precipitation hardenable alloys is still a subject of extensive research. The interaction between the flow localization and dynamic precipitation process has been the subject of very limited research [1-13]. For instance, the retardation of dynamic recrystallization due to dynamic precipitation was tested for HSLA steels [4-7]. It should be noted that the deformation process in HSLA steels have been assumed to be homogeneous. However, the homogeneity of the deformation was not examined during the research cited. There is a shortage of data which refer to specific features of phase transformation processes in precipitation hardenable alloys. Moreover, the existing data does not allow generalizing structural features of DP and simplifying structural description of the process. The experiments on hot deformation of age hardenable alloys and the analysis of DP process have a practical aspect. This interaction could become an important feature of high temperature performance and may also influence the production of specific structures of material. One of the most fundamental features that characterize plastic workability of material is flow stress $\sigma_{\mathrm{pl}}-$ i.e. stress essential for plastic flow initiation and continuation in a one-dimensional stress state [25]. The flow stress value is strongly affected by temperature, deformation value, strain rate and the history of the course of deformation process [5]. To describe the relationship between deformation parameters and stress, the following mathematical formula can be used [6-10]:

$$
\dot{\varepsilon}=\mathrm{A}[\sinh (\alpha \sigma)]^{\mathrm{n}} \cdot \exp \left(\frac{-\mathrm{Q}}{\mathrm{RT}}\right)
$$

where:

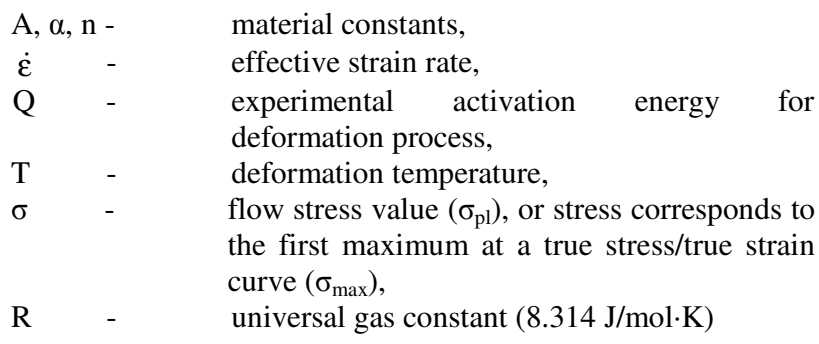

In the case of the small stresses $(\alpha \sigma) \leq 0.39$; the equation (1) can be simplified (value of $\sinh (\alpha \sigma)$ can be approximated by $\approx \alpha \sigma$ with an accuracy $\pm 1 \%$ ) and expressed as:

$$
\dot{\varepsilon}=\mathrm{A}_{1} \sigma^{\mathrm{n}} \cdot \exp \left(\frac{-\mathrm{Q}}{\mathrm{RT}}\right)
$$

where: $\mathrm{A}_{1}=\mathrm{A} \alpha^{\mathrm{n}}-$ material constant

For a large value of the flow stress - $\alpha \sigma>3.9$ (sinh $(\alpha \sigma) \approx 0.5 \exp (\beta \sigma))$ the equation (1) can be modified as follows:

$$
\dot{\varepsilon}=A_{2} \cdot \exp (\beta \sigma) \cdot \exp \left(\frac{-Q}{R T}\right)
$$

where: $A_{2}=A / 2^{n} ; \beta=\alpha n$

It is known that temperature has a significant effect on the flow stress variations during hot forming processes. In addition, a commonly used parameter in description of high-temperature deformation process is the Zener-Holloman parameter. This parameter which is usually known as a flow stress expressed in terms of temperature-compensated strain rate or as a deformation intensity is thought to influence the course of $\sigma=f(\varepsilon)$ function, the flow stress value - maximum $\sigma_{\max }$ and at stationary state $-\sigma_{\mathrm{pl}}$, dynamic recrystallization kinetic and size of dynamically recrystallized grains.

$$
\mathrm{Z}=\dot{\varepsilon} \cdot \exp \left(\frac{\mathrm{Q}}{\mathrm{RT}}\right)
$$

An activation energy for the deformation process, $Q$ (equation (1)(3)) is often characterized for a material and deformation parameters. In the practice, the value of $\mathrm{Q}$ is constant, and depends on the method of forming process and deformation parameters [24]. Therefore its value can be used only for mathematical description of the relation: stress-deformationtemperature. In general, during hot-deformation of a material with high stacking fault energy (Al alloys and ferritic Fe alloys) when a stabilized value of the flow stress results from softening due to dynamic recovery, $\mathrm{Q}$ is close to the value of activation energy for self-diffusion. For materials with low $\mathrm{SFE}(\mathrm{Ni}, \mathrm{Cu}$ and stainless steel), in most cases undergoing both dynamic recovery and recrystallization, $\mathrm{Q}$ is higher than the activation energy for the self-diffusion [6,8]. The aim of this research was to obtain an empirical relationship between the flow stress, phase composition and deformation parameters (deformation temperature, strain rate and cooling during deformation). The measured flow stress allow us to estimate the activation energy for high-deformation process of the examined steel.

The present research work contributes some new information about the precipitation process which occurs in solution treated nickel based superalloy deformed at elevated temperatures and was inspired by the studies of previous researches performed on $\mathrm{Cu}-\mathrm{Ni}-\mathrm{Si}-\mathrm{Cr}-\mathrm{Mg}, \mathrm{Cu}-\mathrm{Ti}$ and low carbon steel $[1-6,14,20]$. The strain/precipitation interaction have revealed much more complex structural processes than those reported for HSLA steels [4]. Nonuniform deformation was observed during hot deformation particularly, which was found to have an effect on dynamic structural processes and, consequently, the structure and mechanical properties of the hot deformed alloys. The plastic instability resulted from the interaction of discontinuous precipitation and shear bands development. The flow localization was accompanied by dynamic particles coarsening within shear 
bands. The flow stress-strain behavior of $\mathrm{Cu}-\mathrm{Ni}-\mathrm{Cr}-\mathrm{Si}-\mathrm{Mg}$ alloy was affected and controlled by dynamic precipitation and its interaction with the strain localization. Additionally, the dynamic coarsening within shear bands was reported to be responsible for further flow softening during hot compression of the material. The shearing process was found to be a self-induced one, i.e. the flow localization accelerated discontinuous precipitation and the precipitation coarsened within the sheared area, which promoted further flow softening. In order to test the interaction of deformation with the precipitation process, hot compression tests were performed on the nickel based superalloy Inconel 718. In718 alloy was chosen since it is hardenable and therefore suitable for testing continuous precipitation interaction with deformation during hot deformation. Thus, the purpose of the described experiments was to study the mechanical behavior and related structural changes that take place during hot deformation of supersaturated Inconel alloy below the solvus temperature (dynamic precipitation conditions). Emphasis was placed on the interaction of precipitation with structural inhomogeneties that may develop during hot deformation. The main goal was to answer the question if the precipitation affects the deformation mode and, if nonuniform deformation induces dynamic coarsening of particles within shear bands. The experimental results may allow a generalized description of the DP process in alloys undergoing multi-step phase transformation including continuous precipitation and discontinuous precipitation.

\section{Material}

In order to investigate the effect of the hardening phases on hot deformation behaviour, the uniaxial, isothermal compression tests at different temperatures and two strain rates were conducted on the solution treated precipitations hardenable nickel based superalloy Inconel 718.

\section{Methodology}

Shear band development and flow localization is expected during hot deformation of Inconel 718 alloy which affects both mechanical behaviour and microstructural features. Precipitation occurs during aging while the samples are compressed making the alloy suitable for studying the interaction of flow localization and dynamic precipitation process. To intensify these phenomenons the alloy has been compressed at two relatively low constant strain rates $\left(10^{-4}, 4 \times 10^{-4} \mathrm{~s}^{-1}\right)$ within the temperature range corresponding to temperatures of precipitation of the hardening phase up to a true strain of 1.9. Elongated compression testing made it possible to reach sufficient deformation and deformation time required for diffusion to control processes developing during the deformation test. Computer-controlled, Gleeble test equipment was used for the compression test (Figure 1).

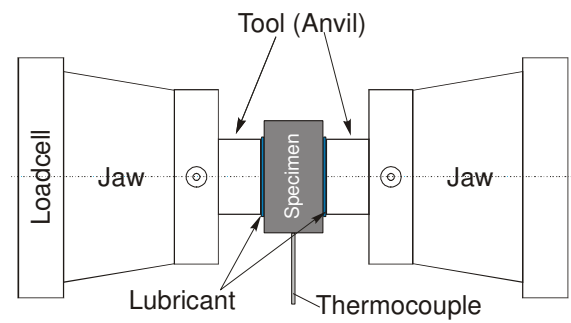

Figure. 1. Outline of the hot compression test and measured parameters in Gleeble thermo mechanical simulator.
The cubicoidal samples $(20 \times 10 \times 20 \mathrm{~mm})$ were conductive heated to $1150^{\circ} \mathrm{C}$ at heating rate of $3^{\circ} \mathrm{C} / \mathrm{s}$, held for $300 \mathrm{~s}$ and finally cooled to the compression temperature. The temperature was controlled by a type $\mathrm{K}$ thermocouple inserted and welded in an opening hollowed out in the central part of the sample by spark erosion technique. Three additional thermocouples were used to acquire the distribution of the temperature from one of the faces to the centre of the specimen. A combination of graphite and molybdenum foils was used to reduce the friction between the anvils and the specimen as well as the gradient of temperature along the specimen. The deformation for all the tests was controlled by the stroke and measured by means of a loadcells attached to the jaws. The tests were carried out in an argon atmosphere. The flow stress values under two different low strain rates over a range of temperatures $\left(720-1150^{\circ} \mathrm{C}\right)$ were measured. Additionally the microstructure was examined using standard optical and electron microscopy techniques, SEM (Hitachi S3400) and TEM (STEM) - (Jeol 2100). The activation energy Q was determined in the following way: by taking the logarithm of eqn (1) the following equation is obtained:

$$
\ln \dot{\varepsilon}=\ln \left(\mathrm{A}\left[\sinh (\alpha \sigma)^{\mathrm{n}}\right)-\frac{\mathrm{Q}}{\mathrm{R}} \cdot \mathrm{T}^{-1}\right.
$$

this can be written in the form:

$$
\left.\frac{\partial \ln \dot{\varepsilon}}{\partial \mathrm{T}^{-1}}\right|_{\sigma}=-\frac{\mathrm{Q}}{\mathrm{R}}
$$

This relation (6) allows us to evaluate the activation energy for a forming process carried out at $\sigma=$ constant, e.g.: creep test. For processes run at constant strain rate the equation (6) is rearranging to the following form:

$$
\left.\frac{\partial \ln \dot{\varepsilon}}{\partial \mathrm{T}^{-1}}\right|_{\sigma}=-\left.\left.\frac{-\partial \ln \dot{\varepsilon}}{\partial \ln [\sinh (\alpha \sigma)]}\right|_{\mathrm{T}} \cdot \frac{\partial \ln [\sinh (\alpha \sigma)]}{\partial \mathrm{T}^{-1}}\right|_{\dot{\varepsilon}}=-\frac{\mathrm{Q}}{\mathrm{R}}
$$

and:

$$
\mathrm{Q}=\left.\left.\mathrm{R} \cdot \frac{\partial \ln \dot{\varepsilon}}{\partial \ln [\sinh (\alpha \sigma)]}\right|_{\mathrm{T}} \cdot \frac{\partial \ln [\sinh (\alpha \sigma)]}{\partial \mathrm{T}^{-1}}\right|_{\varepsilon}
$$

The value of activation energy can be also estimated by applying following formula:

$$
\mathrm{Q}=\frac{\left.\frac{\partial \ln \sigma}{\partial \mathrm{T}^{-1}}\right|_{\dot{\varepsilon}}}{\left.\frac{\partial \ln \sigma}{\partial \ln \dot{\varepsilon}}\right|_{\mathrm{T}}}
$$

\section{Results}

The effect of deformation temperature on the true stress-true strain curves for the alloy deformed at strain rates of: $10^{-4}$; $4 \times 10^{-4} \mathrm{~s}^{-1}$ and temperatures of $720-1150^{\circ} \mathrm{C}$ is shown in Figures 2 and 3 . 


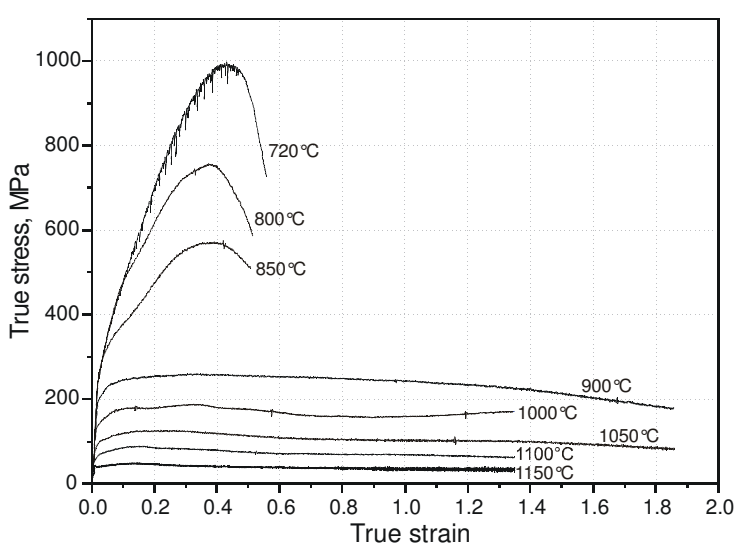

Figure. 2. True stress-true strain curves for Inconel 718 alloy deformed at different temperatures and a strain rate of $10^{-4} \mathrm{~s}^{-1}$ (the deformation temperature was indicated in the figure).

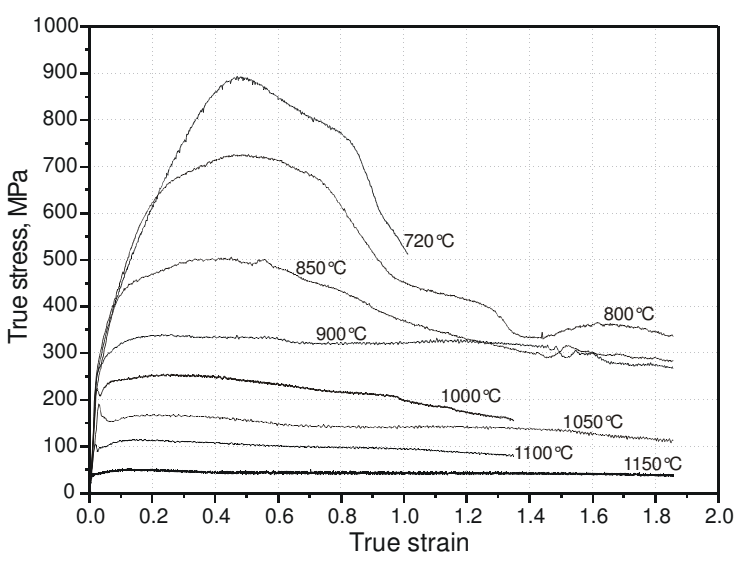

Figure. 3. True stress-true strain curves for Inconel 718 alloy deformed at different temperatures and a strain rate of $4 \times 10^{-4} \mathrm{~s}^{-1}$ (the deformation temperature was indicated in the figure).

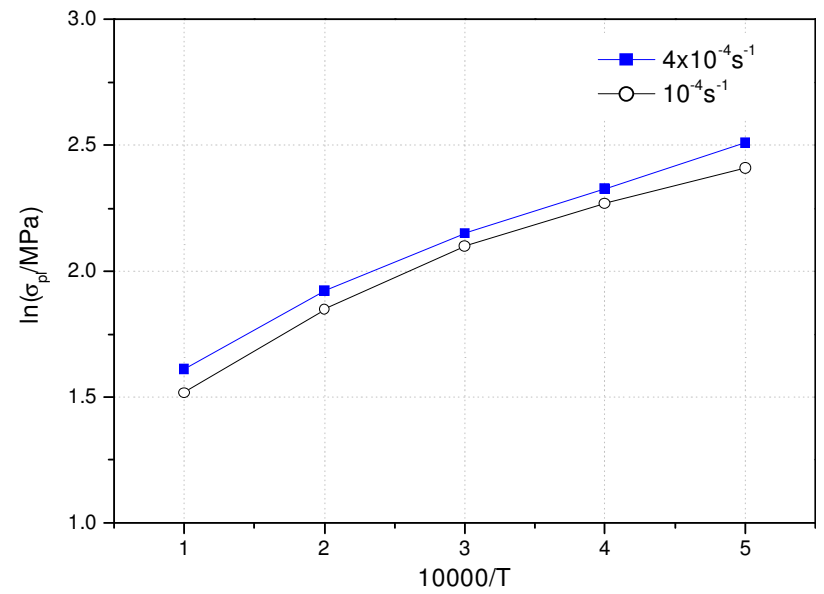

Figure. 4. Relationship between the flow stress and deformation temperature for solution treated Inconel 718.

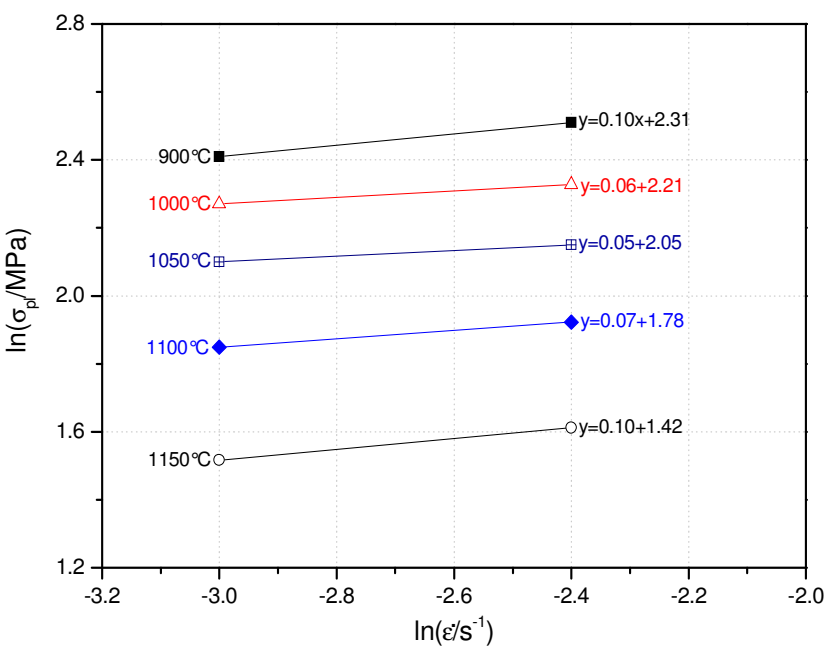

Figure. 5. Relationship between the flow stress and strain rate for solution treated Inconel 718.

The stress-strain curves for both strain rates evaluated do not give a true indication of a stationary plastic flow in the temperature range $\left(720-850^{\circ} \mathrm{C}\right)$ due to fracture of the samples. Therefore, for an evaluation of coefficients required for determination of the $\mathrm{Q}$ value of deformed Inconel alloy, only data obtained in the limited temperature range, where plastic flow was stable, namely 900$1150^{\circ} \mathrm{C}$, have been used. The flow stress can be selected as the representative stress of each true strain-true stress curve. Figure 4 and 5 show the relationship between flow stress on deformation temperature and strain rate, respectively. The classic interdependence of the flow stress and deformation parameters can be seen, namely: the flow stress increased with decreasing deformation temperature and increasing strain rate. This behavior is similar to the results obtained by Guimaraes and Jonas [21].

Based upon the diagrams representing equations of $\ln \sigma_{\max }=\mathrm{f}(1 / \mathrm{T})$ and $\ln \sigma_{\mathrm{pl}}=\mathrm{f}(\ln \dot{\varepsilon}) \quad$ (Fig. 4 and 5), the following values $\left.\frac{\partial \ln \sigma}{\partial \mathrm{T}^{-1}}\right|_{\dot{\varepsilon}} ;\left.\frac{\partial \ln \sigma}{\partial \ln \dot{\varepsilon}}\right|_{\mathrm{T}}$ have been determined. These values were used in the equation (9) to estimate the activation energy for hightemperature deformation process of the investigated Inconel alloy.

For the range of deformation conditions employed, flow stress as a function of deformation temperature and strain rate was analyzed using a hyperbolic-sine Arrhenius type equation [14]. Flow stress vs. deformation temperature and strain rate dependence $\sigma_{\mathrm{pl}}=\mathrm{f}(\dot{\varepsilon}, \mathrm{T})$ was determined based upon both equations (1), (2), (4) and experimental data (Figs. 4 and 5).

$$
\dot{\varepsilon}=3.93 \times 10^{14}[\sinh (\alpha \sigma)]^{2.21} \cdot \exp \left(\frac{-\mathrm{Q}}{\mathrm{RT}}\right)
$$

Activation energy Q for the deformation process of Inconel 718 is strongly affected by temperature and strain rate (Table 1). 
Table I. Activation energy for the Inconel 718 deformed in the temperature range of $900-1150^{\circ} \mathrm{C}$

\begin{tabular}{|c|c|c|c|c|c|}
\hline Strain & \multicolumn{5}{|c|}{ Temperature, ${ }^{\circ} \mathrm{C}$} \\
\hline $\begin{array}{l}\text { rate } \\
\dot{\varepsilon}, \mathrm{s}^{-1}\end{array}$ & 900 & 1000 & 1050 & 1100 & 1150 \\
\hline $10^{-4}$ & 590.1 & 495.7 & 443.0 & 424.9 & 380.05 \\
\hline $4 \times 10^{-4}$ & 550.1 & 461.3 & 412.4 & 395.5 & 353.7 \\
\hline
\end{tabular}

The mean value of activation energy for high-temperature forming in the temperature range of $900-1150{ }^{\circ} \mathrm{C}$ is $450.8 \mathrm{~kJ} / \mathrm{mol}$. For comparison, the activation energy evaluated by Weis [17] was 423 $\mathrm{kJ} / \mathrm{mol}$ and Medeiros et al. [18] - $400 \mathrm{~kJ} / \mathrm{mol}$. Estimated value of activation energy $(\mathrm{Q})$ has a physical meaning and can be used in practice for modeling many types of engineering processes, e.g. analysis of plastic forming using the Finite Element Method. The effect of deformation temperature and strain rate on the flow stress can be expressed by the Zener-Hollomon parameter Z. Fig. 6 shows relationship between the flow stress and the $\mathrm{Z}$ parameter. The flow stress value increased with increasing the $\mathrm{Z}$ parameter.

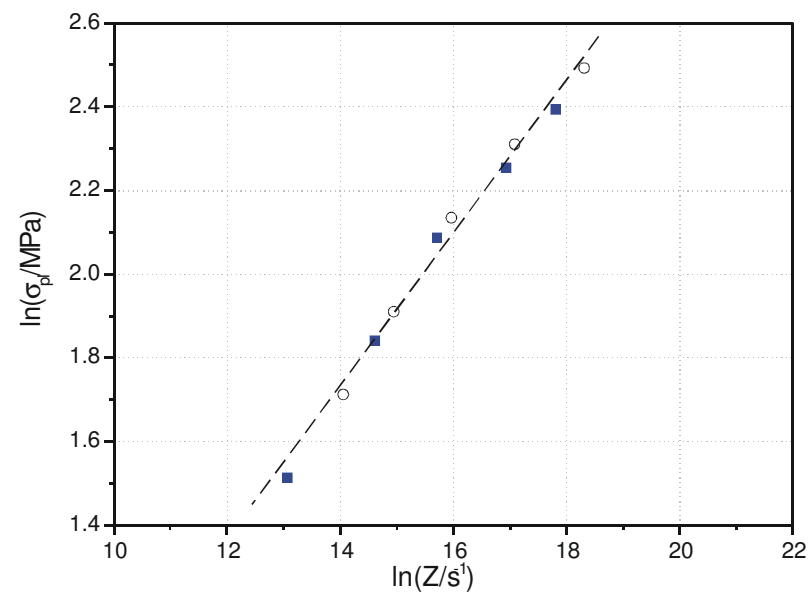

Figure. 6. Relationship between flow stress and the $\mathrm{Z}$ parameter for deformed of solution treated Inconel 718.

One must notice two distinguishable regions on the flow stress curves of the solution treated samples of Inconel alloy deformed at relatively low temperature, namely: 720,800 and $850^{\circ} \mathrm{C}$ and with strain rate of $10^{-4} \mathrm{~s}^{-1}$ (see Fig. 2). The first region, which occurs at an applied strain not exceeding 0.4 , is characterized by almost uniform work hardening to a hump due to effective static precipitation within the alloy. The second region is characterized by a rapid flow softening followed by sample fracture at strain not exceeded the value of $\varepsilon \approx 0.6$ (Fig. 2). However, the flow stress of the samples deformed at these temperatures with higher strain rate $\left(4 \times 10^{-4} \mathrm{~s}^{-1}\right)$ increased to a peak value and then rapidly decreased as the strain further increased (Fig. 3). The typical structure of the solution treated Inconel sample deformed at $720^{\circ} \mathrm{C}$ with a strain rate of $10^{-4} \mathrm{~s}^{-1}$ is shown in Fig. 7. Coarse slip bands in the grain interiors and localized flow shear bands were observed. Nonuniform deformation and coarse slip bands were also observed in the microstructure of the samples of Inconel 718 deformed at 800 and $850^{\circ} \mathrm{C}$ (Fig. 8).

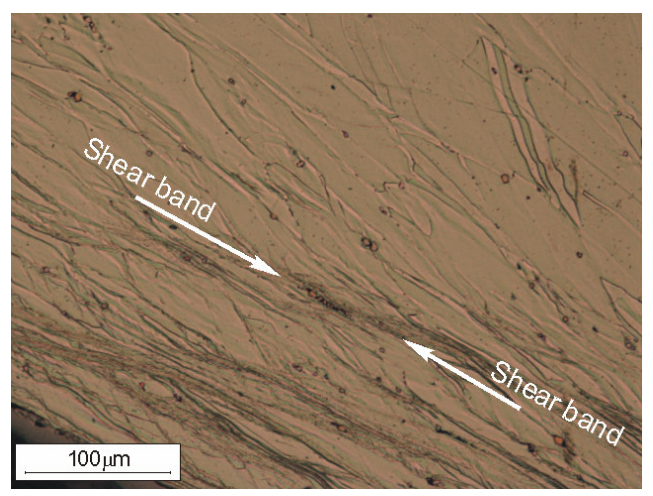

Figure. 7. Micrograph of the alloy deformed at $720^{\circ} \mathrm{C}$, strain rate of $10^{-4} \mathrm{~s}^{-1}$.

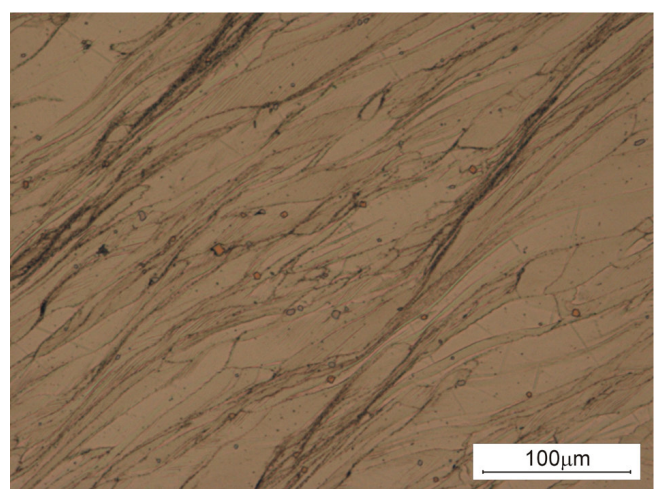

Figure. 8. Optical micrograph for the sample of In718 deformed at $850^{\circ} \mathrm{C}$, strain rate of $4 \times 10^{-4} \mathrm{~s}^{-1}$.

Development of cracks followed by fracture in the flow softening range was also observed in the alloy deformed at these deformation temperatures but at higher strain rate of $4 \cdot 10^{-4} \mathrm{~s}^{-1}$. However, the effect was limited to the central part of the compressed sample and did not cause a failure of the sample before reaching its imposed maximum strain, as occurred in the samples deformed at the same temperatures $\left(720-850^{\circ} \mathrm{C}\right)$ with the lower strain rate $4 \times 10^{-4} \mathrm{~s}^{-1}$ (Fig. 9).

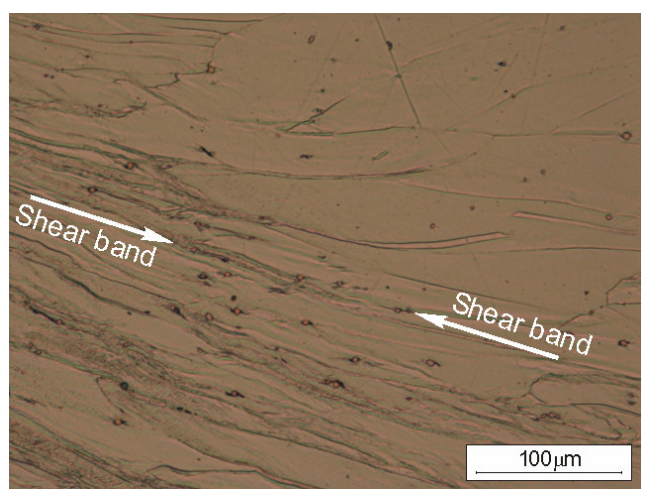

Figure. 9. Microstructure of the sample deformed at $720^{\circ} \mathrm{C}$, strain rate of $4 \times 10^{-4} \mathrm{~s}^{-1}$. 
Microstructural examinations of the samples revealed sites where preliminary flow localization caused localization of the hardening phases. One can see on the micrographs of the Inconel alloy deformed at $720^{\circ} \mathrm{C}$ at both strain rates columnar particles distributed along shear bands (see regions marked with arrows in the Figures 7 and 8). Microshear bands may induce localized shearing within neighboring grains due to the local stress concentration at the grain boundary which results in shear band development throughout those grains.
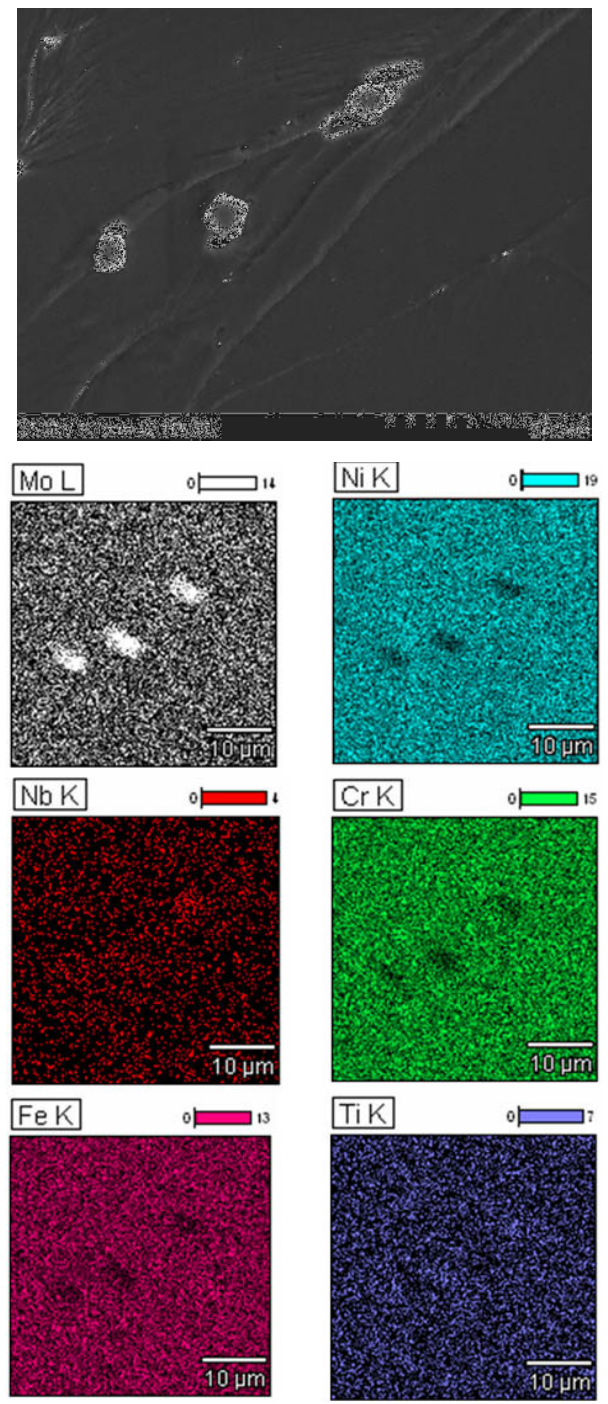

Figure. 10. SEM micrographs of specimens and X-ray mapping results for the precipitates within shear band observed in Inconel

718 alloy deformed at $800^{\circ} \mathrm{C}$ and strain rate of $10^{-4} \mathrm{~s}^{-1}$.

Coarsened particles (Fig. 10) were clearly distinguishable by high magnification SEM. The distribution of these particles was revealed by X-ray mapping on the SEM and indicated coarsened molybdenum-rich particles which were about $3000 \mathrm{~nm}$ in size. TEM observations of the samples deformed at 720 and $850^{\circ} \mathrm{C}$ with both strain rates confirmed that localized deformation may promote intensive dynamic precipitation and coarsening of the particles within shear bands (Fig. 11 - 13). EDS linear analysis from a typical, large particle showed that this type of particle contained mainly $\mathrm{Nb}$, which indicates that these particles are $\mathrm{NbC}$ carbides (Fig. 14).

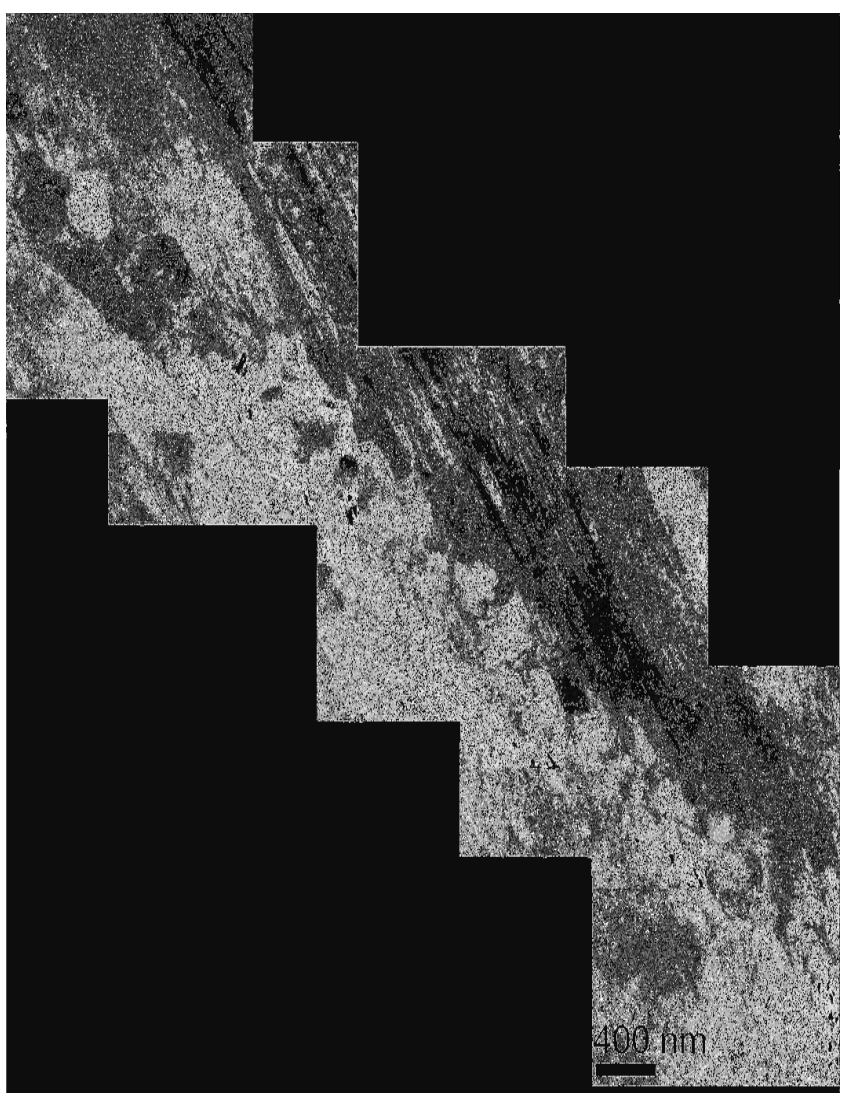

Figure. 11. Typical microstructure of alloy 718 after deformation at $720^{\circ} \mathrm{C}$, strain rate of $10^{-4} \mathrm{~s}^{-1}$. Extensive precipitation within the localized deformation zone can be observed.

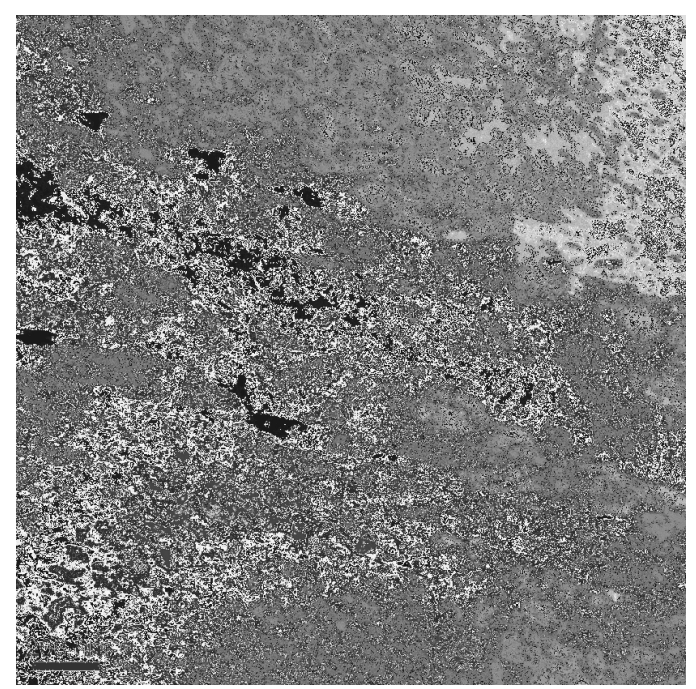

Figure. 12. Microstructure of solution treated samples deformed to 1.8 true strain at $720^{\circ} \mathrm{C}$, strain rate of $4 \times 10^{-4} \mathrm{~s}^{-1}$. 


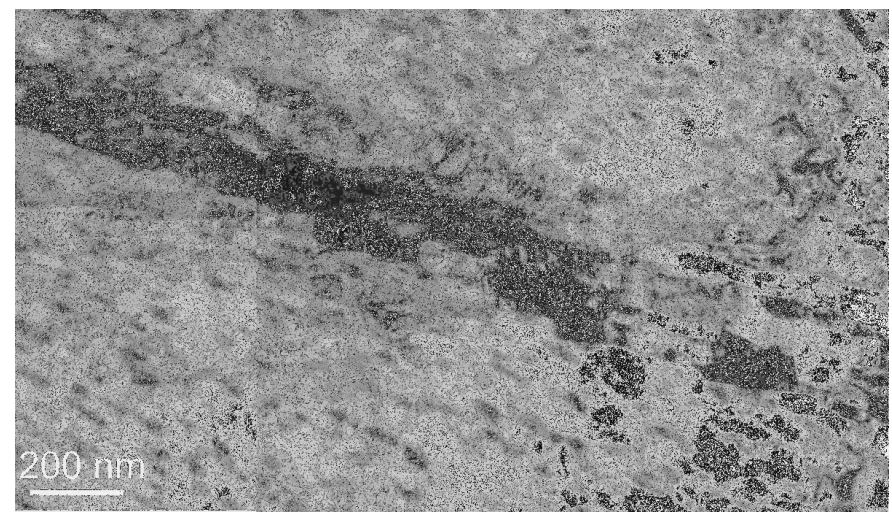

Figure. 13. Microstructure of the alloy subjected to compression test at $850^{\circ} \mathrm{C}$, strain rate of $4 \times 10^{-4} \mathrm{~s}^{-1} \cdot \gamma^{\prime \prime}$ phase precipitation in the matrix and carbides phase precipitation within shear band.

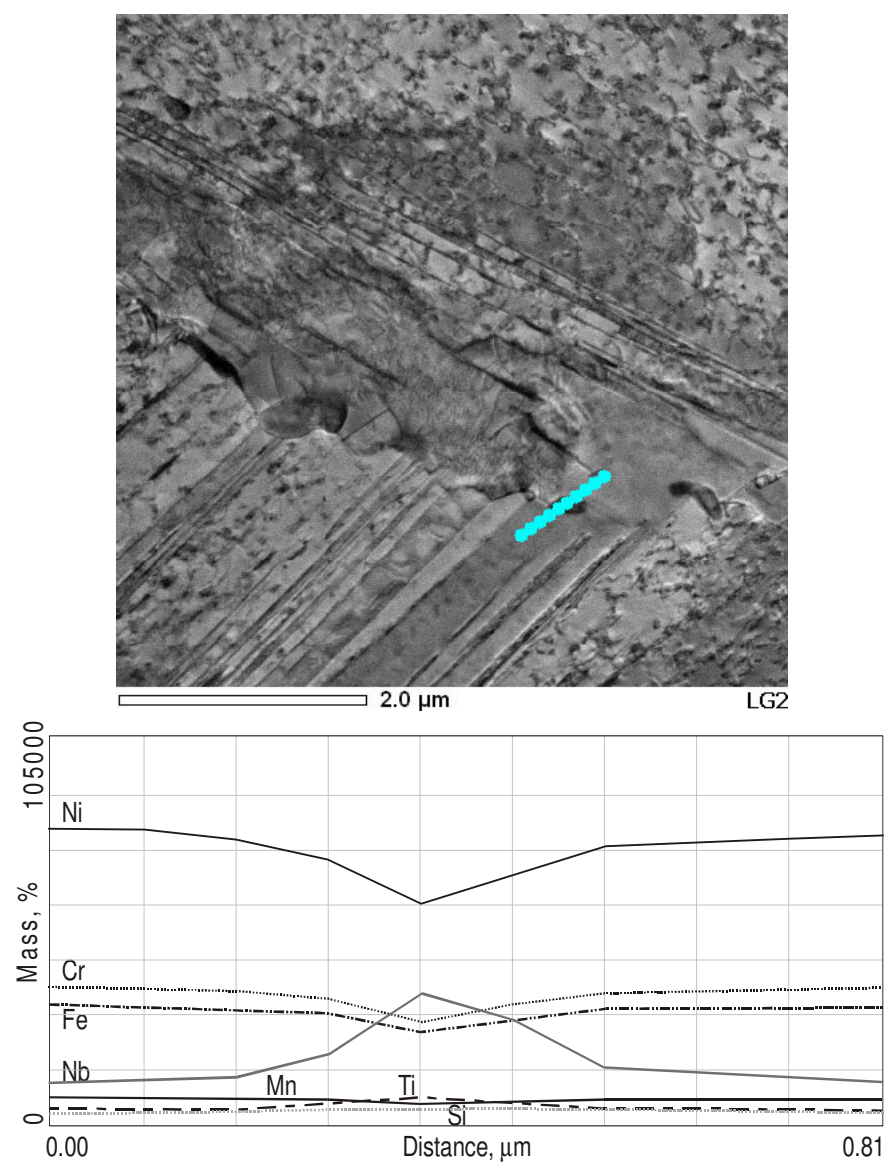

Figure 14. STEM EDS line scan of the particle in the hot deformed Inconel 718 alloy.

Transmission electron microscopy also revealed dispersive particles, less than $50 \mathrm{~nm}$ in size within grains interior (Fig. 13 15). However STEM resolution was not high enough to distinguish smaller particles by mapping techniques. Literature relating to precipitate characterization after an isothermal age performed following quenching allowed them to be identified as $\gamma^{\prime \prime}$ phase precipitations.

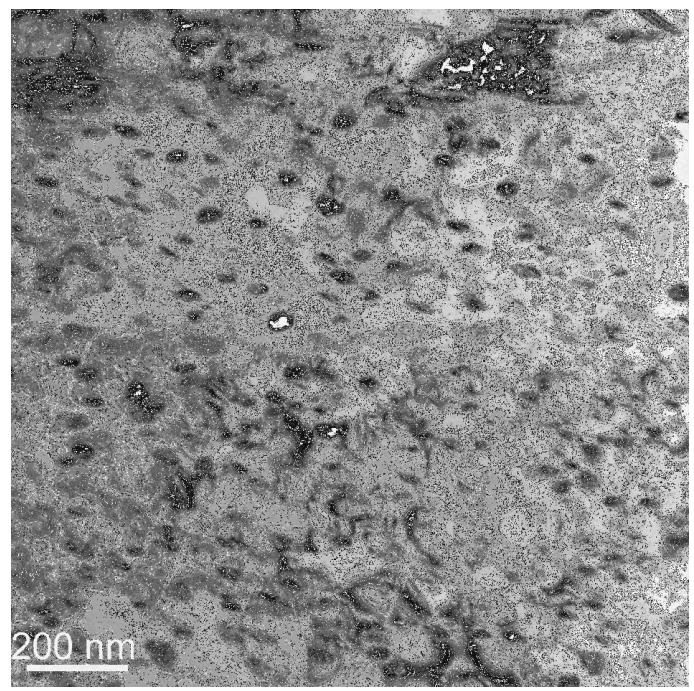

Figure. 15. Precipitation of $\gamma^{\prime \prime}$ phases observed in the microstructure of the alloy deformed at $900^{\circ} \mathrm{C}$.

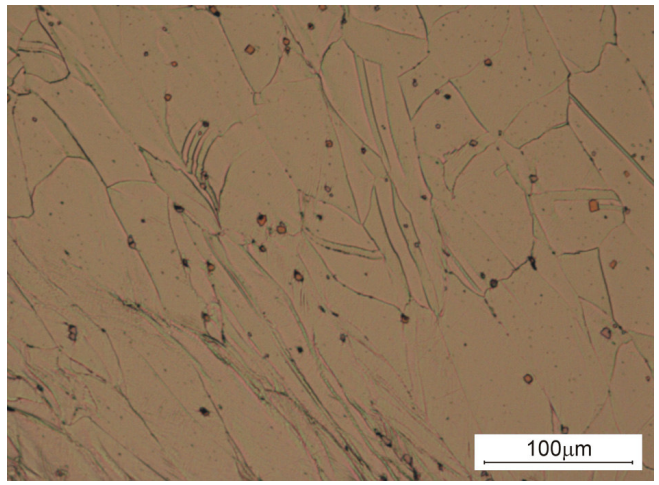

Figure. 16. Optical micrograph for the sample of In718 deformed at $900^{\circ} \mathrm{C}$, strain rate of $10^{-4} \mathrm{~s}^{-1}$.

A steady state flow stress range, following the flow stress maximum, was observed during high temperature deformation $\left(900,1000,1050,1100\right.$ and $1150^{\circ} \mathrm{C}$ ) (Figs. 2 and 3). A single peak stress-strain curve observed at high temperatures has resulted from dynamic recrystallization. The characteristic shape of the stress-strain curves indicated that the structural softening mechanism for the alloy deformed at higher temperatures was limited to the dynamic revocery. However, it was noted that dynamic recrystallization was a process which has a crucial effect on the final value of the flow stress (Fig. 16-19). From this point of view, it seems clear why there was no indication of fracture or flow localization and why no arrangement of precipitations due to heterogeneous deformation was detected. 


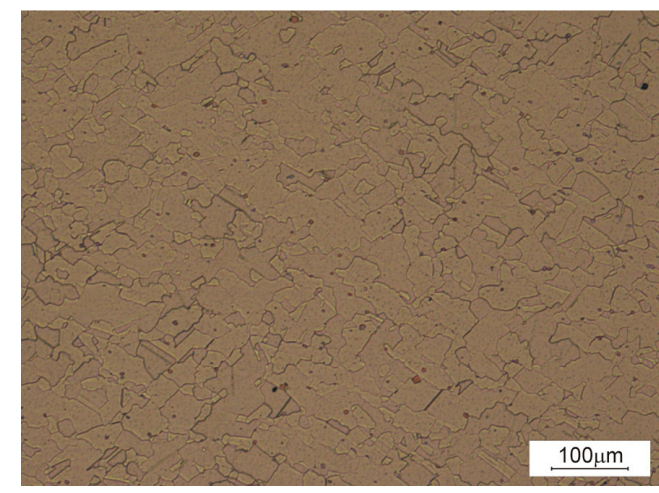

Figure. 17. Optical micrograph for the sample of In718 deformed at $1050^{\circ} \mathrm{C}$, strain rate of $4 \times 10^{-4} \mathrm{~s}^{-1}$.

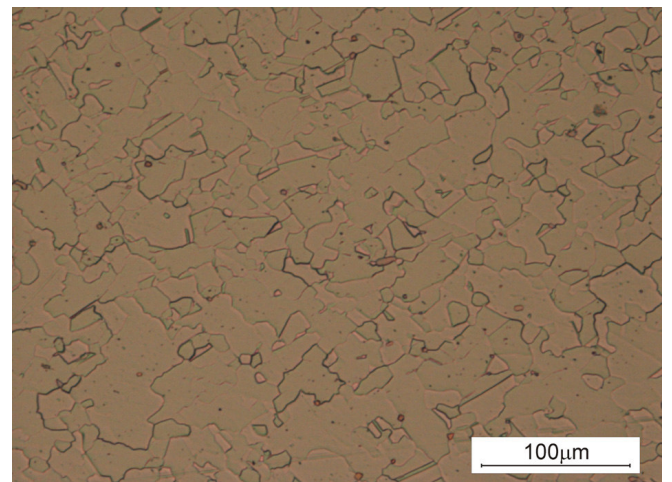

Figure. 18. Optical micrograph for the sample of In 718 deformed at $1150^{\circ} \mathrm{C}$, strain rate of $10^{-4} \mathrm{~s}^{-1}$.

Microstructural observations after the compression testing detected dynamically recrystallized grains containing subgrains see Figure 19.

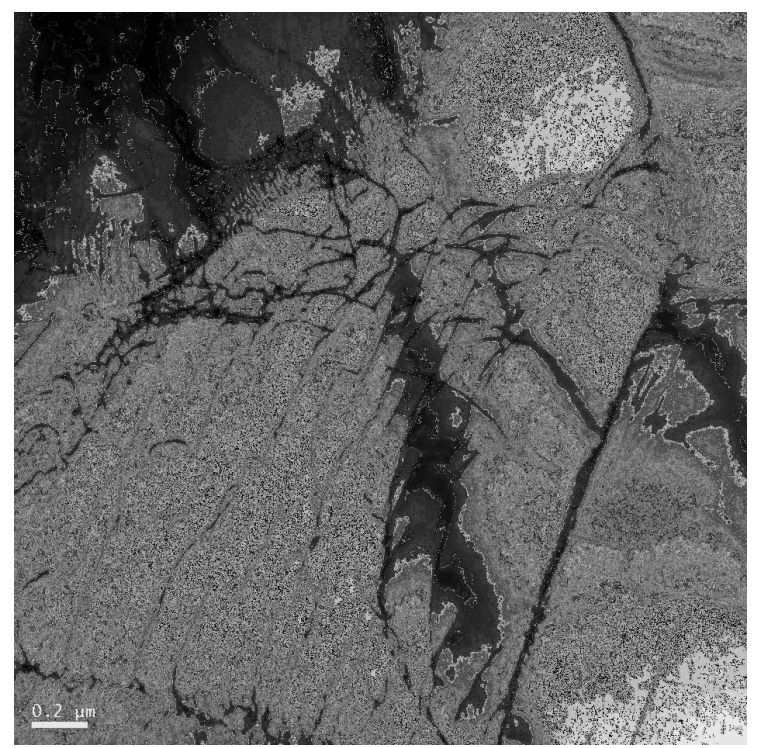

Figure. 19. TEM micrograph of the specimen deformed at $1150^{\circ} \mathrm{C}$, strain rate of $10^{-4} \mathrm{~s}^{-1}$.

\section{Conclusions}

Isothermal hot compression tests were conducted at low constant rate in order to evaluate the affect of dynamic precipitation and deformation processes on the mechanical properties of Inconel 718. Therefore solution treated samples were compressed at elevated temperatures to induce precipitation due to overlapping of deformation process and recrystallization. Decreasing the value of strain rate by 4 results in about $18 \%$ flow stress reduction. Shear banding and intergranural cracking was intensified within the temperature range of $720-900^{\circ} \mathrm{C}$. Microstructural observations suggested that intergranular cavities growth was responsible for load decrease and the fracture of the material. TEM investigations of the specimens deformed at lower temperatures, confirmed that the strain localization in shear bands and microshear bands plays an important role during the entire process of deformation. Localization of precipitates within shear bands was observed for the samples deformed at $720-850^{\circ} \mathrm{C}$. It was found that most of the carbides that precipitate within shear bands resulting from ongoing deformation process were $\mathrm{Nb}$-rich particles. These are hypothesized to be $\mathrm{Nb}$ carbides. A general conclusion follows from the consideration of the role of shear banding in the material structure - this particular mode of deformation may be used as a method of microstructure control. Oriented arrangement of the secondary phases may significantly reinforce the strength of a material without deterioration of the material ductility, as it was observed in case of $\mathrm{Fe}-\mathrm{Ni}$ [6] and $\mathrm{Cu}$ alloys [1-3]. It is interesting to consider a condition when shear bands are formed in deformed material. These localized fields of internal stresses usually show some spatial distribution with long range periodicity. Since shear bands act as preferred sites for nucleation of second phases, the arrangement of the products of decomposition of unstable matrix should also reflect this periodicity. Hence, one may anticipate in the microstructure of the compressed material linear ordering of hardening phases similar to the distribution of shear bands, as well as their significant influence on the mechanical properties of material.

The relationship between deformation parameters and a maximum flow stress value was described by equation (2). Basing on the diagrams - Fig. 3 and 4, the factors from the equation (9) were determined in order to estimate the mean value of activation energy (Q) of high-temperature deformation process of examined Inconel $718-\mathrm{Q}=450.8 \mathrm{~kJ} / \mathrm{mol}$. The results (Table 2) show that activation energy depends on temperature and strain rate. Analogous dependence of deformation parameters on the value of activation energy was observed in other alloys systems and metals $[19,20]$. One cannot, however, generalize in respect to the strain rate and temperature, the tendency in the change of activation energy for all type of materials. It is worth to emphasize that any particular single structural process could not be ascribed to the value of energy activation. Change of fraction of thermally activated dynamic recovery process and dynamic recrystallization in depreciation of the flow stress value is due to variation of the deformation parameters. It would be almost impossible to draw distinction between these processes on the grounds of an energy activation value. Therefore, averaging $Q$ values obtained from the deformation within wide temperature and strain rate range should be treated as a mathematical treatment allowing one to determine constants in the equation describing the relationship between deformation parameters and flow stress value. The relationship between the flow stress, deformation temperature and strain rate can be described by the following equation:

$$
\dot{\varepsilon}=3.93 \times 10^{14}[\sinh (\alpha \sigma)]^{2.21} \cdot \exp \left(\frac{-450.8}{\mathrm{RT}}\right)
$$


The results of high-temperature deformation of the superalloy Inconel 718 may possibly find some practical use in the workshop practice to predict a flow stress values, but only within particular temperature and strain rate ranges. Dissimilar energy activation values obtained under various conditions (depending on a research centre) or for a variety of materials make it impossible to do a direct comparison of measurements, e.g. by means of plotting them on one common graph $\sigma_{\mathrm{pl}}=\mathrm{f}(\mathrm{Z})$. One should stress that a mathematical description of the relationship between deformation conditions is attributed for the range characteristic for the presence of particular phase. Thus, the equation (3) solely refers to the range of $900-1150^{\circ} \mathrm{C}$.

It is worth to mention, the work reported here was undertaken as a part of a study with a view to characterize the development of the microstructure under dynamic deformation condition - to verify if this alloy is prone to produce preferred nucleation of particles at shear bands (SBs) which was considered as an effective tool for the production of a specific particle distribution in some $\mathrm{Al}$ and $\mathrm{Cu}$ alloys; not for precise identification of the intermetallic phases that occur in this alloy after compression at various temperatures and strain rates.

\section{Acknowledgements}

This work was carried out with the financial support of the Ministry of Science and Higher Education under grant No. N507 115 31/2788.

\section{References}

1. M. Niewczas, E. Evangelista, L. Błaż, "Strain localization during a hot compression test of Cu-Ni-Cr-Si-Mg alloy", Scripta Metallurgica et Materialia, 27 (1992) 1735-1740.

2. A. A. Hameda, L. Błaż, "Microstructure of hot-deformed Cu3.45 wt.\% Ti alloy, Materials Science and Engineering, A254 (1998) 83-89.

3. A. A. Hameda, L. Błaż, "Flow Softening During Hot Compression of Cu-3.45wt.\%Ti Alloy", Scripta Materialia, 12 (1997) 1987-1993.

4. J. J. Jonas, I. Weiss, "Effect of precipitation on recrystallization in microalloyed steels", Material Science and Engineering, 13 (1979) 238-245.

5. A. Korbel et al., Proceedings: Symposia sponsored by the Extraction and Processing Division, held at the TMS Annual Meeting in Ontario, Florida USA (1997) 301-312.

6. A. Korbel et al., "The 'natural' metal-matrix composite formation by thermo-mechanical treatments,", Journal of Materials Processing Technology, 78 (1998) 104-111.

7. A. Nowotnik, L. Błaż, J. Sieniawski, "Phase deformation in $0.16 \% \mathrm{C}$ steel under hot deformation conditions" (Paper presented at the Seminar Devoted to the 70th Birthday Anniversary of Prof. Z. Jasieński, Kraków 2005) 213-218.

8. A. Nowotnik, L. Błaż, J. Sieniawski, "Interaction of phase transformation and deformation process during hot deformation of 0.16\%C steel", Defect and Diffusion Forum, 237-240 (2005) 1240-1245.
9. C.M. Sellars, W.J. Tegart, "La relation entre le resistance et la structure dans la deformation a chaud", Membr. Sci. Rev. Met., 63 (1966) 731-746.

10. S.F. Medina, C.A. Hernandez, "Modelling austenite flow curves in low alloy and microalloyed steels", Acta Metall., 44 (1996) 137.

11. W.J. Weis in: E.A. Lodia, Superalloy 718 - Metallurgy and Applications, TMS Warrendale, PA (1989) 161.

12. S.C. Madeiros, et al., "Microstructural Modeling of Recrystallization in hot working of IN 718 superalloy", Mater. Sci. Eng. A293 (2000) 198-207.

13. A. Nowotnik et al., "Austenite decomposition in carbon steel under dynamic deformation conditions", J. Achievements in Materials Engineering, 20 (2007) 1-2 105-108.

14. C.M. Sellars, W.J. Tegart, "Progresses in Fracture and Strength of Materials and Structures" Membr. Sci. Rev. Met., 63 (1966) 731-740.

15. X.X. Xia, H.J. Sakaris, H.J. McQueen, "Hot deformation, dynamic recovery and recrystallisation behaviour of aluminium 6061-SiCp composite”, Mater. Sci. Technol. 10 (1994) 487-496.

16. B. Lopez, J.J. Urcola, "Hot deformation characteristics of Inconel 625”, Mater. Sc. Technol. 12 (1996) 673-678.

17. W.J. Weis, in: E.A. Loria (Ed.) Superalloy 718 - Metallurgy and Applications: Hot Deformation Behavior of an As-Cast Alloy 718 Ingot TMS, Warrendale, PA (1989) 135-154.

18. S.C. Medeiros et al., "Microstructural modeling of metadynamic recrystallization in hot working of IN 718 superalloy", Mater. Sci. Eng. A293 (2000) 198.

19. R. Sandstörm, "A model for static recrystallization after hot deformation”, Acta Metallurgica, 23, (1975) 481-489.

20. A.J. Mc Laren, C.M. Sellars, "Modelling distribution of microstructure during hot rolling of stainless steel", Materials Science and Technology, 8 (1992) 1090-1098.

21. A.A. Guimaraes, J.J. Jonas, "Recrystallization and aging effects associated with the high temperature deformation of waspaloy and inconel 718", Metall. Trans. 12 (1981) 1655-1666.

22. C. Slama, M. Abdellaoui, "Structural characterization of the aged 718", J. Alloys and Compounds 306 (2000) 277-284.

23. M. Sundararaman, R. Kishore, P. Mukhopadhyay, "Strain hardening in underaged INCONEL 718", Metallurgical and Materials Transactions 25A (1994) 653-656.

24. W. Roberts, Deformation, Processing and Structure (Metals Park, OH: American Society for Metals, 1985), 109-184.

25. F. Grosman, Placticity of the alloys, Ustron (1996) 11-18. 